\title{
A new approach for vibration and noise control of a floor-standing conditioner
}

\author{
Ligui Xiong1, Xingni Peng ${ }^{2}$ \\ Guangdong Polytechnic Institute, Zhongshan, China \\ ${ }^{2}$ Corresponding author \\ E-mail: ${ }^{1} 119970291 @ q q . c o m,{ }^{2} 1049661754 @ q q . c o m$
}

Received 22 March 2021; received in revised form 8 April 2021; accepted 18 April 2021 DOI https://doi.org/10.21595/vp.2021.21963

Check for updates

Copyright $(2021$ Ligui Xiong, et al. This is an open access article distributed under the Creative Commons Attribution License, which permits unrestricted use, distribution, and reproduction in any medium, provided the original work is properly cited.

\begin{abstract}
Based on the CAE simulation analysis technology, the dynamic analysis of the sheet metal parts of a certain type of household cabinet air conditioner, combined with the results of the noise diagnosis analysis, realizes the modal vibration optimization of the sheet metal parts by changing the design parameters of the stiffeners, and improves the performance of the sheet metal parts. Vibration and noise reduction performance. The test results show that after optimization, the noise and vibration radiation of the sheet metal parts of the air conditioner is reduced, and the sound quality of the air conditioner is significantly improved.
\end{abstract}

Keywords: vibration and wave, split air conditioner, CAE, vibration reduction and noise reduction.

\section{Introduction}

With the improvement of the quality of life, people have higher and higher requirements for the quality of household appliances, and pay more attention to the sound quality of household appliances. For household appliances companies, the sound quality of products is undoubtedly very helpful to the improvement of product competitiveness. Air-conditioning products are no exception, and consumers' requirements for sound quality continue unabated. Due to my country's relative grid harmonic content requirements standards Wider and lack of supervision. For different areas and different times, the high harmonic content of the power grid causes power distortion, which has led to prominent noise problems in cabinets in recent years. On the one hand, it can improve the anti-harmonic ability of the motor; on the other hand, it can reduce the sheet metal. Respond to parts and optimize the dynamic performance of the structure.

Regarding the relationship between the vibration and noise radiation of sheet metal parts and other plates, it is also a hot spot in vibration control research. Domestic and foreign scholars never Study the relationship between vibration and noise radiation from the same angle, hoping to reveal its internal connection and find a physical quantity that can directly measure sound radiation. Some scholars use FEM and BEM simulation technology to study the relationship between stiffened panels and acoustic radiation [1-3]; some scholars need to reduce acoustic radiation through model optimization, and also propose the relationship between acoustic radiation mode and noise radiation and so on [4-6].

Nowadays, the noise level of air conditioners has become a simple way for people to judge the quality of air conditioners. It is also an important standard to measure the performance of air conditioners. The development of air conditioners needs to follow a green and environmentally friendly route, and it is necessary to effectively reduce the noise during operation of the air conditioner [5-8]. However, most work the noise reduction of the researcher or researcher only considers the noise generated by traditional reasons such as compressor operation, motor operation, air flow, mechanical pipes and so on.

This article introduces a new vibration and noise reduction technology. The research puts forward the design of the sheet metal structure of the air conditioner, which will also affect the noise generated during the operation of the air conditioner, and the vibration and noise reduction 
technology can be achieved through innovative structural design methods. This will provide reference and reference for the development of new air conditioners and the quality of noise reduction in the future.

In this paper, combined with the "buzzing" problem of the cabinet-type internal machine, the compression parameters of the rear plate are analyzed from the response end, and the fixed frequency and mode shape of the rear plate structure are optimized using finite element dynamics analysis technology to improve the reduction of the rear plate. Vibration and noise reduction performance improves the sound quality of air conditioners [9-12].

\section{Research on structural parameters of air conditioning sheet metal}

The dynamic performance of the structure is determined by the structural form. The sheet metal parts used in air conditioning components have the following two problems: 1) The thickness of the sheet metal parts is thin $(0.6-1.15 \mathrm{~mm})$; 2) The area of the sheet metal parts is large.

The above problems not only lead to poor structural strength, but also seriously affect the dynamic performance of the structure, resulting in vibration and noise reduction performance difference. Under the premise of not increasing the cost, the structural performance can be changed by adding stiffener design. But how to ensure that the structural strength is increased at the same time, it can improve the vibration and acoustic performance of the structure. It is necessary to carry out optimization research on the parameters of the bead (the depth of the bead $h$, the width of the bead $b$ ). Considering the problem of springback deformation, the mold technology has specific requirements for the depth of the bead. This article only studies the influence of the width of the bead on the structure's fixed frequency and structural dynamic response.

\subsection{Simplification and establishment of finite element model}

Combined with the analysis of the noise and vibration transmission path of the cabinet machine, from the excitation end to the response end, an important transmission path directly related to the "buzzing": motor $\rightarrow$ damping rubber pad $\rightarrow$ positioning bolt $\rightarrow$ rear plate, so the electromagnetic "buzzing" To deal with the "acoustic" problem, the analysis model is simplified into a rear plate and motor model.

The simplified analysis model is meshed. Considering that the sheet metal is large and thin, the shell element shell63 is used for simulation; the motor mainly considers the influence of quality, and the shell element shell63 is also used for simulation. The quality is established by modifying the material density to ensure the quality. Finite element model [13-15].

Boundary constraint: the rear plate adopts four-sided full displacement constraint, and the motor and the rear plate are connected by node coupling.

\subsection{Dynamic analysis under different compression parameters}

\subsubsection{Modal analysis under different reinforcement parameters}

Do not change the way of back slab crimping, only change the width of crimping to compare the results of modal analysis. The specific data is shown in Table 1, focusing on the comparison of the solid frequency around $100 \mathrm{~Hz}$ of excitation frequency.

Through the comparison of simulation data, the above-mentioned structural modal parameters show that:

1) When the width of the ribs is $26,28,30(\mathrm{~mm})$, the natural frequency of the structure deviates from the excitation frequency of the motor by a large amplitude of $100 \mathrm{~Hz}$, which is not easy to cause resonance.

2) At the same time, considering the difference between the simulation of the bolt connection 
and the actual connection in the simulation process, the actual structure stiffness is somewhat different rise.

Comprehensive analysis shows that when the rib width is $26,28,30(\mathrm{~mm})$, the structure can effectively avoid the excitation frequency.

Table 1. Structural modal solid frequency comparison parameters

\begin{tabular}{|c|c|c|c|c|c|}
\hline \multirow{2}{*}{ Order } & Tendon width & Tendon width & Tendon width & Tendon width & Tendon width \\
& 16 & 18 & 20 & 22 & 24 \\
\hline 13 & 86.3 & 87.5 & 89.1 & 90.7 & 92.3 \\
\hline 14 & 94.2 & 96.3 & 98.3 & 100.1 & 101.7 \\
\hline 15 & 98.5 & 100.4 & 102.2 & 103.7 & 105.2 \\
\hline 16 & 109.1 & 111.9 & 114.2 & 116.2 & 117.8 \\
\hline \multirow{2}{*}{ Order } & Tendon width & Tendon width & Tendon width & Tendon width & Tendon width \\
& 26 & 28 & 30 & 32 & 34 \\
\hline 13 & 93.6 & 94.9 & 95.9 & 96.8 & 97.6 \\
\hline 14 & 103.2 & 104.6 & 105.7 & 106.8 & 107.7 \\
\hline 15 & 106.5 & 107.6 & 108.7 & 109.6 & 110.3 \\
\hline 16 & 119.3 & 120.4 & 121.3 & 122.2 & 122.8 \\
\hline
\end{tabular}

\subsubsection{Harmonic response analysis under different compression parameters}

In order to determine the structure's displacement and stress changes under the action of harmonic load, a harmonic response analysis was carried out. The modal analysis results show that the bead width is $26,28,30(\mathrm{~mm})$ is better, so the harmonic response analysis is carried out for the above situation. The selected motor model is LN90X, the technical parameters are output power $64 \mathrm{~W}$, speed $530 \mathrm{r} / \mathrm{min}$, torque $1.15 \mathrm{~N} \cdot \mathrm{m}$. The load applied by the simulation is a torque of $1.15 \mathrm{~N} \cdot \mathrm{m}$ and a frequency of $100 \mathrm{~Hz}$.

Table 2. Harmonic response analysis results of different rib widths

\begin{tabular}{|c|c|c|c|c|c|}
\hline Tendon width $(\mathrm{mm})$ & $\mathrm{Ux}(\mathrm{mm})$ & $\mathrm{Uy}(\mathrm{mm})$ & $\mathrm{Uz}(\mathrm{mm})$ & $\mathrm{Usum}(\mathrm{mm})$ & SEQV $(\mathrm{MPa})$ \\
\hline 26 & 94.2 & 96.3 & 98.3 & 100.1 & 101.7 \\
\hline 28 & 98.5 & 100.4 & 102.2 & 103.7 & 105.2 \\
\hline 30 & 109.1 & 111.9 & 114.2 & 116.2 & 117.8 \\
\hline
\end{tabular}

The harmonic response analysis of different rib widths shows that:

1) Compared with the harmonic response analysis results of different compression bar widths, the result of the stiffener being $28 \mathrm{~mm}$ is the best.

2) When the bead width is $28 \mathrm{~mm}$, the maximum displacement and maximum stress of the harmonic response analysis structure are $0.00204 \mathrm{~mm}, 0.656027 \mathrm{MPa}$.

3 ) The results also show that the structure of the motor installation parts is relatively weak and needs to be further strengthened. Consider pressing the cross ribs at the convex hull.

\subsubsection{Calculate the sound insulation of thin plates}

The FE-SEA method is used to calculate the sound insulation of the sample, and the calculation formula is:

$S_{T L}=10 \lg \frac{E_{\text {in }}}{E_{\text {out }}}=10 \lg \frac{p^{-2} S /(4 \mathcal{P} c)}{I S}$,

where $S_{T L}$ is the sound insulation of sheet metal parts; $E_{\text {in }}$ is the incident sound energy; $E_{\text {out }}$ is the transmitted sound energy; $p^{-2}$ is the mean square value of the sound pressure at multiple points in the reverberation room; $S$ is the area of the tested sample; $\mathcal{P}$ is the air density; $c$ is the 
speed of sound; $I$ is the sound intensity of the tested sample.

The FE-SEA method can effectively predict the sound insulation performance of the sample, and therefore provides an idea for the calculation of the sound insulation of the air-conditioning sheet metal reinforcement ribs.

\section{Optimization analysis of internal structure of split cabinet air conditioner}

For after-sales feedback models with noise problems, the reinforcement ribs are optimized, and the optimal plan is confirmed through the fixed frequency and mode shape distribution and experimentally verified.

\subsection{Structural model optimization}

The analysis results show that the width of the ribs is set to be $28 \mathrm{~mm}$. The model comparison before and after optimization shows that the ribs adopt a "\#"-shaped structure, which reduces the width between ribs and reduces the deformation between ribs.

\subsection{Finite element modal analysis}

According to the aforementioned analysis results, the dynamic performance of the rear plate structure is evaluated, and the motor has little influence. Therefore, the modeling and analysis of the rear plate and its reinforced parts are directly used to obtain the evaluation of the fixed frequency and mode shape.

Table 3. Natural frequency parameter table of the original rear plate

\begin{tabular}{|c|c|c|c|c|c|}
\hline Order & 1 & 2 & 3 & 4 & 5 \\
\hline Fixed frequency & 15.7 & 19.9 & 25.1 & 26.9 & 34.8 \\
\hline Order & 6 & 7 & 8 & 9 & 10 \\
\hline Fixed frequency & 41.1 & 42.0 & 45.6 & 52.2 & 54.6 \\
\hline Order & 11 & 12 & 13 & 14 & 15 \\
\hline Fixed frequency & 62.7 & 64.3 & 70.4 & 76.8 & 79.2 \\
\hline Order & 16 & 17 & 18 & 19 & 20 \\
\hline Fixed frequency & 79.6 & 84.0 & 85.4 & 89.9 & 91.8 \\
\hline Order & 21 & 22 & 23 & 24 & 25 \\
\hline Fixed frequency & 94.2 & 102.0 & 102.9 & 109.2 & 112.8 \\
\hline
\end{tabular}

The above table is the old natural frequency table. After optimized design and improvement, the natural frequency parameters of the rear panel are as follows.

Table 4. Optimized natural frequency parameter table of rear plate

\begin{tabular}{|c|c|c|c|c|c|}
\hline Order & 1 & 2 & 3 & 4 & 5 \\
\hline Fixed frequency & 26.8 & 31.8 & 32.9 & 40.7 & 50.8 \\
\hline Order & 6 & 7 & 8 & 9 & 10 \\
\hline Fixed frequency & 53.9 & 63.6 & 67.5 & 75.3 & 81.7 \\
\hline Order & 11 & 12 & 13 & 14 & 15 \\
\hline Fixed frequency & 86.2 & 97.4 & 99.5 & 104.9 & 107.4 \\
\hline Order & 16 & 17 & 18 & 19 & 20 \\
\hline Fixed frequency & 119.9 & 126.2 & 126.7 & 135.7 & 137.8 \\
\hline Order & 21 & 22 & 23 & 24 & 25 \\
\hline Fixed frequency & 146.9 & 151.1 & 154.0 & 159.7 & 161.9 \\
\hline
\end{tabular}

The analysis results before and after optimization is shown in Table 3 and Table 4 . The results show that:

1) After optimization, the rigidity of the structure is greatly improved, and the low-order fixed 
frequency is increased from $15.7 \mathrm{~Hz}$ to $26.8 \mathrm{~Hz}$.

2) Compared with the excitation frequency $(100 \mathrm{~Hz})$, the fixed frequency is closer to the excitation frequency after optimization, but the vibration shape is significantly improved. The maximum vibration area is located at the bottom. Considering that the bottom mounting base is made of plastic parts, it is good for vibration energy dissipation. The upper large area has less vibration.

In summary, the overall effect of the scheme after optimization combined with fixed frequency and mode shape distribution is better than before optimization.

\section{Experimental verification}

Perform noise comparison tests on the rear panel installation before and after optimization. In order to ensure the authenticity of the experimental test, only the noise conditions of the low and high windshields before and after optimization are compared under the same test environment.

The noise test of the old sheet metal structure air conditioner is carried out in the noise test room first, and the low wind and high windshield are tested separately. The measured result is the noise condition before optimization $(37.6 \mathrm{~dB}(\mathrm{~A}) / 23.7 \mathrm{~dB}(\mathrm{~A}) / 395.5 \mathrm{~Hz})$, as shown in Fig. 1.

The structural sheet metal of the floor-mounted split air conditioner was replaced with new and optimized structural parts, and the noise test was carried out under the same working conditions, and the low wind and high windshield were tested separately. The measured result of the optimized noise is $(35.6 \mathrm{~dB}(\mathrm{~A}) / 20.9 \mathrm{~dB}(\mathrm{~A}) / 395.5 \mathrm{~Hz})$, the optimized noise is reduced by $2 \mathrm{~dB}(\mathrm{~A})$, and the noise reduction effect is achieved.

As shown in Figs 1 and 2, the test results show that the total noise value of the optimized rear panel and before optimization is reduced, and the peak of electromagnetic noise $(100 \mathrm{~Hz}, 200 \mathrm{~Hz}$, $300 \mathrm{~Hz}$ ) is not obvious, and the sound quality of the whole machine is improved.

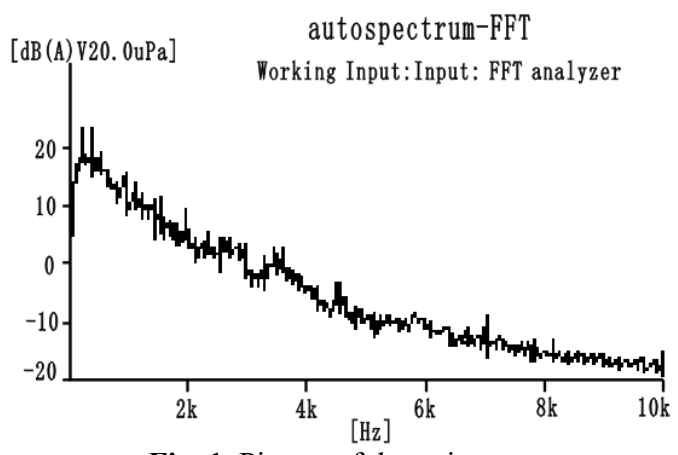

Fig. 1. Picture of the noise test of the old sheet metal structure

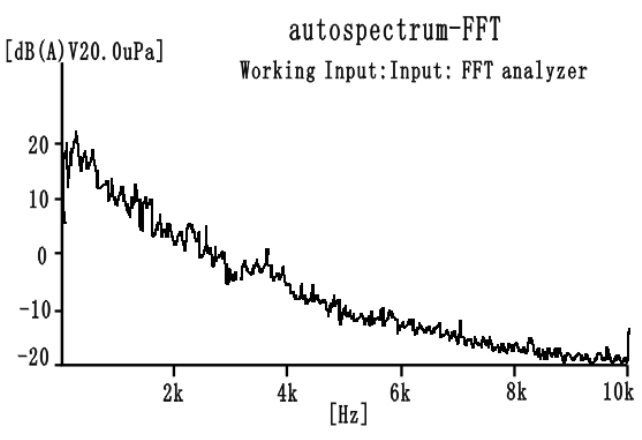

Fig. 2. Picture of optimized sheet metal structure noise test

\section{Conclusions}

In addition to the traditional methods of air conditioner vibration and noise reduction technology, this article proposes a new effective noise reduction method. This result can be widely used in household floor-standing air conditioner indoor products, creating a relatively quiet living environment for people.

The vibration reduction and noise reduction technology studied in this paper are mainly technical solutions such as the innovation of the air conditioning sheet metal "\#"-shaped compression rib structure, the material performance of the sheet metal, and the strength of the motor installation position to minimize noise.

Through the finite element dynamics analysis and experimental verification of the sheet metal parts of the rear panel of the cabinet-type air conditioner, the comparative analysis results show that: 
1) Changing the bead parameter, that is, the width of the bead, the modal and harmonic response analysis results show that under the condition that the thickness of the sheet metal part does not change, the comprehensive effect of the bead width is $28 \mathrm{~mm}$.

2) In terms of the layout of the ribbed structure, simulation and test results verify that the "\#"-shaped ribbed structure is adopted, and the structural rigidity has been greatly improved, which is beneficial to vibration and noise reduction.

3) The vibration and noise reduction analysis of the machine in the cabinet shows that the strength of the installation position of the motor is of great significance to the overall vibration reduction and isolation. Need to focus on the vibration shape and stiffness of the place.

4) Vibration and noise reduction of sheet metal parts not only need to consider the deviation of the solid frequency from the motor excitation frequency to prevent resonance. Because the sheet metal parts used are thin in thickness and high modal density, it is sometimes difficult to avoid the excitation frequency, so the noise reduction is more it is important to optimize the vibration shape to avoid a large vibration concentration area.

\section{References}

[1] Alicja Kowalska Koczwara Influence of location of measurement point on evaluation of human perception of vibration. Journal of Measurements in Engineering, Vol. 7, Issue 3, 2019, p. 147-154.

[2] Souici Rania, et al. Identification of vibration direction of existing buildings using ambient vibration noise tests. Arabian Journal of Geosciences, Vol. 14, Issue 1, 2021, p. 189-206.

[3] Shi Hui, et al. Improving camper comfort by optimizing the vibration isolation of air-conditioning compressor. Mathematical Problems in Engineering, Vol. 2020, 2020, p. 156-163.

[4] Hattori Takahiro Noise as a liquidity measure: evidence from the JGB market. Pacific-Basin Finance Journal, Vol. 67, 2021, p. 101515.

[5] Sun Dengmin Research on optimization design of stiffened plate structure and sound radiation based on FEM-BEM. Nanjing: Jiangsu University of Science and Technology, Vol. 26, Issue 8, 2018, p. $42-45$.

[6] Zuo Shuguang, et al. Optimal design of plate structure based on acoustic radiation control. Journal of Tongji University (Natural Science Edition), Vol. 40, Issue 1, 2019, p. 28-32.

[7] Chen Meixia, et al. Analysis of the relationship between vibration and radiation noise of stiffened cylindrical shell structure. China Ship Research, Vol. 5, Issue 2, 2016, p. 38-42.

[8] Shi Wei Research and control on vibration and sound radiation of rectangular thin plates. Chengdu: Southwest Jiaotong University, Vol. 15, Issue 6, 2015, p. 6-15.

[9] Zang Xianguo, et al. Structural acoustic radiation control based on modal shape optimization. Chinese Journal of Mechanical Engineering, Vol. 46, Issue 9, 2018, p. 33-37.

[10] Liu Chengwu, et al. Study on the modal characteristics of compressor body acoustic radiation. Fluid Machinery, Vol. 34, Issue 12, 2016, p. 25-28.

[11] Cheng Pengyu, et al. Analysis of rotating noise of domestic air conditioner. Home Appliance Technology, Vol. 13, Issue 8, 2015, p. 20-23.

[12] Cheng Zhenggen, et al. Research on the source, diagnosis and noise reduction of air-conditioning noise. Technology Vision, Vol. 21, Issue 7, 2015, p. 28-32.

[13] Zhang Jun, et al. Vibration and noise reduction treatment of air-conditioning refrigeration room. China's New Technology and New Products, Vol. 11, Issue 3, 2019, p. 31-34.

[14] Jia Limin, et al. Patent analysis of noise reduction technology for outdoor unit of air conditioner. Henan Science and Technology, Vol. 21, Issue 10, 2018, p. 19-23.

[15] Feng Jinping Tone evaluation of air-conditioning indoor unit based on sound-to-noise ratio. Household Appliances, Vol. 22, Issue 9, 2017, p. 35-28. 